Article

\title{
Characteristics of Individuals with Disagreement between Home and Ambulatory Blood Pressure Measurements for the Diagnosis of Hypertension
}

\author{
Chee Hae Kim ${ }^{1, \dagger}$, Je Sang Kim ${ }^{1, \dagger}$ and Moo-Yong Rhee ${ }^{1,2, *}$ \\ 1 Cardiovascular Center, Dongguk University Ilsan Hospital, Goyang 10326, Korea; \\ chhkim@dumc.or.kr (C.H.K.); drjesang@dumc.or.kr (J.S.K.) \\ 2 College of Medicine, Dongguk University, Gyeongju-si, Gyeongbuk 38066, Korea \\ * Correspondence: mooyong_rhee@dumc.or.kr; Tel.: +82-31-961-5775 \\ + These authors contributed equally to this work.
}

Received: 18 September 2020; Accepted: 29 October 2020; Published: 3 November 2020

check for updates

\begin{abstract}
Home and ambulatory blood pressure (BP) measurements are recommended for the diagnosis of hypertension. However, the clinical characteristics of individuals showing a diagnostic disagreement between their home and ambulatory BP measurements are unclear. Of the 470 individuals who were not on antihypertensive drug treatment with a $\mathrm{BP} \geq 140 / 90 \mathrm{mmHg}$ at an outpatient clinic, 399 who had valid office, home, and ambulatory BP results were included. Hypertension was diagnosed based on an average home BP $\geq 135 / 85 \mathrm{mmHg}$ and/or an average daytime ambulatory BP $\geq 135 / 85 \mathrm{mmHg}$. The participants were divided into three groups: Agree-NT (home and ambulatory BP normotension), Disagree (home BP normotension and ambulatory BP hypertension, or home BP normotension and ambulatory BP hypertension), and Agree-HT (home and ambulatory BP hypertension). Eighty-four individuals (21.1\%) were classified as the Disagree group. The mean serum creatinine, triglycerides, and electrocardiogram voltage in the Disagree group were intermediate between those observed in the Agree-NT and the Agree-HT group. In the Disagree group, the mean levels of office and home diastolic BP, all of the components of ambulatory BP, the aortic systolic $\mathrm{BP}$, and the $\mathrm{BP}$ variabilities were found to be intermediate between those of the Agree-NT and the Agree-HT groups. These results indicate that individuals showing a diagnostic disagreement between their home and ambulatory BP may have cardiovascular risks that are intermediate between those with sustained home and ambulatory normotension and hypertension.
\end{abstract}

Keywords: hypertension; out-of-office blood pressure; home blood pressure measurements; ambulatory blood pressure measurements; disagreement

\section{Introduction}

Accurate blood pressure (BP) measurements are essential for the diagnosis and treatment of hypertension [1]. Office BP measurements have been widely used to monitor BP because they are conveniently and rapidly obtained, but they are easily confounded by various factors [2]. Therefore, current guidelines recommend out-of-office blood pressure measurements for the optimal diagnosis and treatment of hypertension $[1,3]$. Both home and ambulatory BP measurements provide BP values based on multiple measurements, reflect BP variations, and have the ability to identify white-coat or masked hypertension, which are commonly misdiagnosed by using office BP only. Furthermore, home $\mathrm{BP}$ and ambulatory BP showed a better association with a future cardiovascular risk or target organ damage compared to office BP [4-6].

Although home and ambulatory BP measurements have similar advantages over office BP measurements, are evenly recommended to confirm the diagnosis of white-coat and 
masked hypertension in the current guidelines, and share the same threshold for hypertension (i.e., $\geq 135 / 85 \mathrm{mmHg}$ for home BP and for the daytime ambulatory BP) [1,3], they can provide different $\mathrm{BP}$ values and result in contradictory diagnoses. However, the clinical characteristics of individuals that exhibit diagnostic disagreement between home BP and ambulatory BP measurements, and whether they should be diagnosed as normotension or hypertension, are still undetermined.

Accordingly, we aimed to identify the clinical characteristics of individuals related to diagnostic disagreement between home and ambulatory BP measurements.

\section{Materials and Methods}

\subsection{Study Population}

From November 2015 to November 2019, 470 individuals who were not on antihypertensive drug treatment with BP of $\geq 140 / 90 \mathrm{mmHg}$, measured by doctors at the outpatient clinic, were prospectively screened. The exclusion criteria were as follows: secondary hypertension, hypertensive emergency or urgency, heart failure (New York Heart Association functional class III or VI), ischemic heart or peripheral arterial disease within the previous 6 months, significant arrhythmia, night labor or shift work, pregnancy, history of drug or alcohol abuse within the previous 6 months, and taking drugs known to affect BP, such as steroids, monoamine oxidase inhibitors, oral contraceptives, or sympathomimetics. Three hundred and ninety-nine individuals with valid office, home, and ambulatory BP measurements were finally analyzed. The study protocol was approved by the Institutional Review Board of the hospital, and all of the study subjects provided written informed consent (Clinicaltrial.gov NCT03855605).

\subsection{Measurements of Office, Home, and Ambulatory BP}

The schedule used for the BP measurements was similar to that used in our previous study $[7,8]$. Briefly, on the first visit day, office BP was measured and instruction for home BP measurements was given to the participants by the study nurse. The home BP measurements started from the evening of the first day, then continued for 7 to 9 consecutive days, and ended in the morning of the 8th to 10th day. On the last day of the home BP measurements, all of the participants visited the clinical trial center of the hospital to measure the second office BP, and to start the 24-h ambulatory BP measurements. On the following day, when the 24-h ambulatory BP measurements had been obtained, the third office BP was measured. During the measurement period, the participants were asked to maintain their daily activities.

The office BP was measured using a validated oscillometric device (WatchBP Office, Microlife, Taiwan) while seated, at both arms, three times, with 1-min intervals, and during the three visits, after a 5-min rest. For the home BP measurements, the participants were instructed to take three measurements at 1-min intervals every morning, after micturition and before breakfast (between 07:00, or waking, and 09:00) and every evening (between 21:00 and 23:00, or bedtime) for 7 to 9 consecutive days, while seated in a quiet place, after 5-min rest, using the provided device (WatchBP Home, Microlife, Taiwan). A valid measurement for a home BP was defined as being at least 5 days of morning and evening measurements. The ambulatory BP monitoring over $24 \mathrm{~h}$ was performed on the non-dominant arm using an automated, noninvasive oscillometric device (Mobil-O-Graph, I.E.M. $\mathrm{GmbH}$, Germany) with a measurement interval of $30 \mathrm{~min}$. The participants were instructed to continue their normal daily activities during the ABP measurements. A valid measurement for the ambulatory $\mathrm{BP}$ was defined as being valid readings for more than $70 \%$ of all of the measurement attempts, and at least 14 measurements during the daytime (09:00 to 21:00) and at least seven measurements during the nighttime (00:00 to 00:60). Blood samples were obtained after an overnight fast of at least $8 \mathrm{~h}$. 


\subsection{Definition of Hypertension}

All three morning and evening home BP readings for whole study days [7] and the daytime ambulatory BP readings (09:00 to 21:00 h) were averaged for each participant. The BP thresholds for the diagnosis of hypertension were defined as an average systolic $\mathrm{BP}$ (SBP) of $\geq 135 \mathrm{mmHg}$, and/or an average diastolic BP (DBP) of $\geq 85 \mathrm{mmHg}$ for home and daytime ambulatory BP measurements [3]. The classification of the office SBP and DBP (optimal, normal, high normal and hypertension) were determined according to the latest guidelines [3].

\subsection{Statistical Analysis}

The participants were classified into three groups according to their diagnosis of hypertension based on their home BP and ambulatory BP measurements: Agree-NT (home BP and ambulatory BP sustained normotension), Disagree (home BP normotension and ambulatory BP hypertension, or home BP hypertension and ambulatory BP normotension), and Agree-HT (home BP and ambulatory $\mathrm{BP}$ sustained hypertension). The BP variability was assessed using the standard deviations (SD) of averaged intra-visit and inter-visit office, home, and ambulatory BP.

The continuous variables were expressed as means \pm standard deviations, and categorical variables were expressed as numbers (percentages). The intergroup differences were analyzed using analysis of variance, with post-hoc comparisons for continuous variables and the chi-square test was used for categorical variables, respectively. Multivariate linear regression analysis was used to determine the effects of the independent variables on the difference between home and ambulatory BP. A generalized multinomial logistic regression for three diagnostic categories was applied to identify the predictors of diagnostic disagreement, including independent variables of age, sex, body mass index, smoking status, alcohol drinking, estimated glomerular filtration rate (eGFR) calculated by using the Chronic Kidney Disease Epidemiology Collaboration (CKD-EPI) creatinine equation, diabetes mellitus, office $\mathrm{BP}$, home BP and ambulatory BP. Two-sided $p$ values $<0.05$ were considered statistically significant. The analyses were performed using SPSS version 22.0 (IBM Co., Armonk, NY, USA) and MedCalc Version 19.0 (MedCalc Software Ltd., Ostend, Belgium).

\section{Results}

\subsection{Participants' Characteristics}

Of the 470 participants, 399 who had valid office, home, and ambulatory BP measurements were finally analyzed and classified into the Agree-NT group ( $n=56,14.0 \%$ ), the Disagree group ( $n=84,21.1 \%$ ), and the Agree-HT group $(n=259,64.9 \%$ ) (Figure 1). The baseline characteristics of the participants are summarized in Table 1 . The participants in the Disagree group were significantly older than those in the Agree-HT group. The proportions of male participants were $26.8 \%, 42.9 \%$, and $54.4 \%$ in the Agree-NT, the Disagree, and the Agree-HT groups, respectively $(p<0.001)$. The creatinine and triglyceride levels of the Disagree group were intermediate between those of the Agree-NT and the Agree-HT groups, with significant differences. The mean electrocardiography Sokolow-Lyon voltage (the voltage of the S wave in V1 + the voltage of the R wave in V5 or V6) of the Disagree group was also between those of the Agree-NT and the Agree-HT groups. 


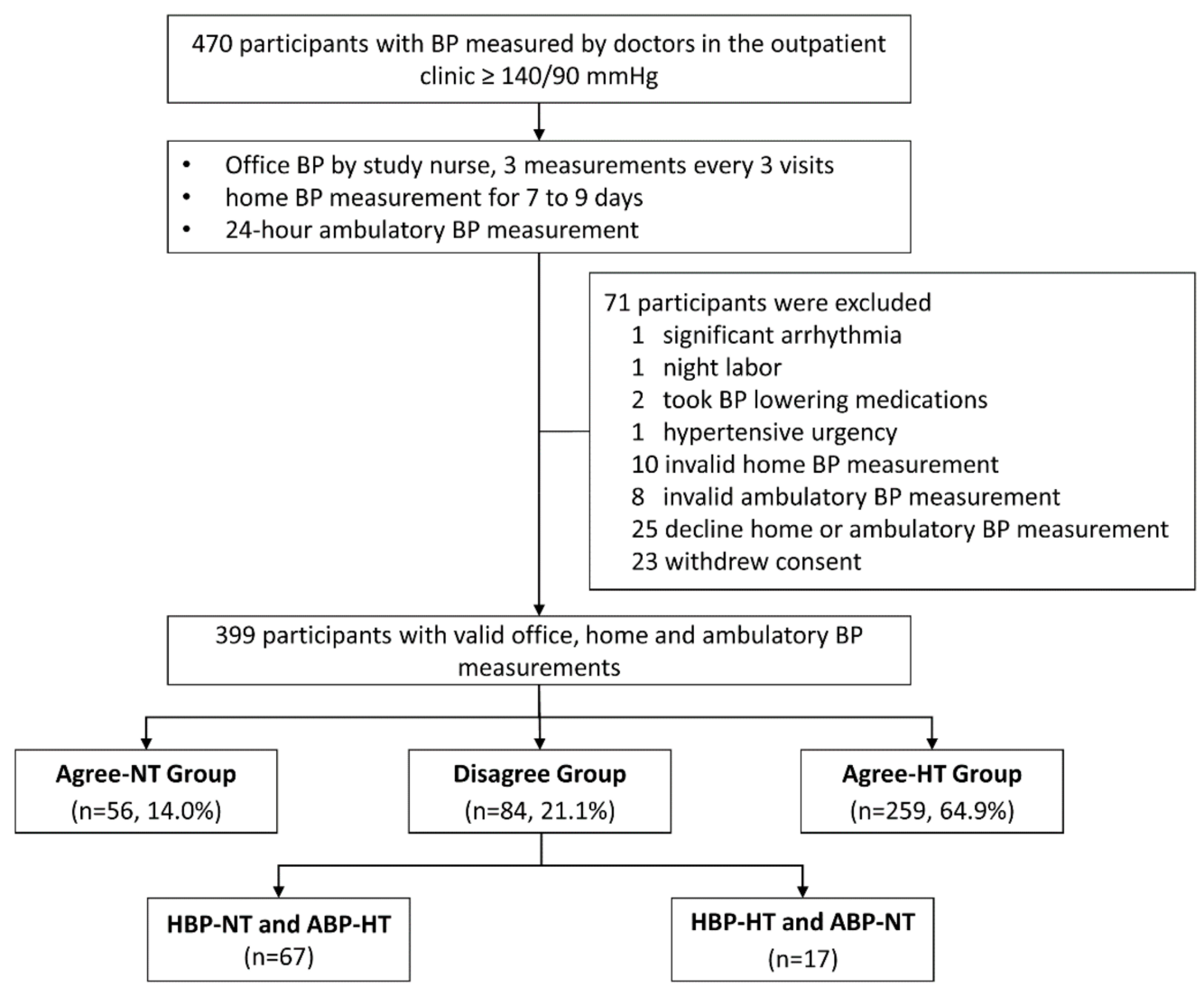

Figure 1. Patients' dispositions. BP, blood pressure; Agree-NT group, home and daytime ambulatory normotension; Disagree group, home normotension and daytime ambulatory hypertension, or home hypertension and daytime ambulatory normotension; Agree-HT group, home and daytime ambulatory hypertension; HBP-NT, home blood pressure normotension; ABP-HT, ambulatory blood pressure hypertension; HBP-HT, home blood pressure hypertension; ABP-NT, ambulatory blood pressure normotension.

Table 1. Baseline clinical characteristics of the study subjects.

\begin{tabular}{|c|c|c|c|c|}
\hline & $\begin{array}{c}\text { Agree-NT } \\
(N=56)\end{array}$ & $\begin{array}{l}\text { Disagree } \\
(N=84)\end{array}$ & $\begin{array}{l}\text { Agree-HT } \\
(N=259)\end{array}$ & $p$-Value * \\
\hline \multicolumn{5}{|l|}{ Clinical characteristics } \\
\hline Age, years & $56.1 \pm 11.0^{a}$ & $55.9 \pm 9.6^{\mathrm{a}}$ & $50.6 \pm 9.9^{b}$ & $<0.001$ \\
\hline Sex, male & $15(26.8 \%)$ & $36(42.9 \%)$ & $141(54.4 \%)$ & $<0.001$ \\
\hline Body mass index, kg/m2 & $24.7 \pm 3.8$ & $25.1 \pm 3.5$ & $25.5 \pm 3.3$ & 0.292 \\
\hline Diabetes mellitus & $2(3.6 \%)$ & $9(10.8 \%)$ & $22(8.5 \%)$ & 0.306 \\
\hline Current smoking & $2(3.6 \%)$ & $7(8.3 \%)$ & $54(20.8 \%)$ & $<0.001$ \\
\hline \multicolumn{5}{|l|}{ Laboratory findings } \\
\hline Creatinine, $\mathrm{mg} / \mathrm{dL}$ & $0.72 \pm 0.15^{\mathrm{a}}$ & $0.77 \pm 0.20^{\mathrm{a}, \mathrm{b}}$ & $0.79 \pm 0.17^{b}$ & 0.017 \\
\hline eGFR & $97.2 \pm 11.5$ & $95.4 \pm 13.9$ & $98.1 \pm 13.1$ & 0.250 \\
\hline Glucose, mg/dL & $103.3 \pm 13.5$ & $103.0 \pm 16.6$ & $105.1 \pm 24.3$ & 0.677 \\
\hline Hemoglobin A1c, \% & $5.69 \pm 0.44$ & $5.69 \pm 0.74$ & $5.73 \pm 0.77$ & 0.872 \\
\hline Total cholesterol, mg/dL & $204.0 \pm 36.1$ & $194.2 \pm 33.1$ & $199.2 \pm 32.8$ & 0.227 \\
\hline Triglycerides, mg/dL & $122.6 \pm 55.8^{a}$ & $132.7 \pm 63.4^{\mathrm{a}, \mathrm{b}}$ & $158.8 \pm 102.4^{b}$ & 0.006 \\
\hline HDL-cholesterol, mg/dL & $57.8 \pm 16.1$ & $54.8 \pm 13.6$ & $54.3 \pm 15.1$ & 0.279 \\
\hline
\end{tabular}


Table 1. Cont.

\begin{tabular}{ccccc}
\hline & $\begin{array}{c}\text { Agree-NT } \\
(\mathbf{N}=\mathbf{5 6})\end{array}$ & $\begin{array}{c}\text { Disagree } \\
(\mathbf{N}=\mathbf{8 4})\end{array}$ & $\begin{array}{c}\text { Agree-HT } \\
(\mathbf{N}=\mathbf{2 5 9 )}\end{array}$ & $p_{\text {-Value * }}$ \\
\hline Laboratory findings & & & & \\
\hline LDL-cholesterol, mg/dL & $136.0 \pm 32.3$ & $131.4 \pm 30.9$ & $132.7 \pm 31.0$ & 0.691 \\
Urine albumin-to-creatinine ratio, & $20.1 \pm 81.0$ & $26.4 \pm 102.7$ & $25.3 \pm 76.8$ & 0.905 \\
ECG voltage, $\mathrm{mV}$ & $2.2 \pm 0.6^{\mathrm{a}}$ & $2.3 \pm 0.7^{\mathrm{a}, \mathrm{b}}$ & $2.5 \pm 0.7^{\mathrm{b}}$ & 0.007 \\
\hline
\end{tabular}

Data are presented as means \pm standard deviation or numbers (percentages). ${ }^{*} p$-value given by the analysis of variance, where the different superscript alphabets $(a$ and $b$ ) represent significant differences at an alpha level of 0.05 , as given by the post hoc Tukey's HSD analysis. Abbreviations: HDL-cholesterol, high-density lipoprotein cholesterol; LDL-cholesterol, low-density lipoprotein cholesterol; ECG, electrocardiogram; eGFR, estimated glomerular filtration rate. The eGFR values were calculated using the CKD-EPI creatinine equation. The ECG voltages were calculated using the Sokolow-Lyon voltage (defined as the voltage of the S wave in V1 + the voltage of the R wave in V5 or V6).

\subsection{Comparisons of BP among the Groups}

Table 2 shows the BP of the three groups. The individuals in the Disagree group had significantly higher office DBP; home DBP; and 24-h, daytime, and nighttime ambulatory BP than those in the Agree-NT group (all $p<0.001$ ). However, all of the BP measurements in the Disagree group were significantly lower than those in the Agree-HT group (all $p<0.001$ ). Regarding the office BP category, the majority of the Disagree group had a high normal SBP and DBP (51.2\% and 33.3\%, respectively) or hypertensive SBP and DBP (35.7\% and 32.1\%, respectively) (Figure 2).

Table 2. Comparison of blood pressure.

\begin{tabular}{ccccc}
\hline & $\begin{array}{c}\text { Agree-NT } \\
(\mathbf{N}=\mathbf{5 6})\end{array}$ & $\begin{array}{c}\text { Disagree } \\
(\mathbf{N}=\mathbf{8})\end{array}$ & $\begin{array}{c}\text { Agree-HT } \\
(\mathbf{N}=\mathbf{2 5 9 )}\end{array}$ & $p$-Value * \\
\hline Office BP measurements & & & \\
\hline Office SBP, mmHg & $134.1 \pm 7.7^{\mathrm{a}}$ & $137.4 \pm 7.8^{\mathrm{a}}$ & $145.3 \pm 10.2^{\mathrm{b}}$ & $<0.001$ \\
Office DBP, mmHg & $82.8 \pm 6.7^{\mathrm{a}}$ & $87.0 \pm 5.6^{\mathrm{b}}$ & $95.6 \pm 7.8^{\mathrm{c}}$ & $<0.001$ \\
\hline Home BP measurements & & & \\
\hline Home SBP, mmHg & $124.3 \pm 6.3^{\mathrm{a}}$ & $127.9 \pm 6.5^{\mathrm{a}}$ & $141.4 \pm 10.6^{\mathrm{b}}$ & $<0.001$ \\
Home DBP, mmHg & $76.5 \pm 5.7^{\mathrm{a}}$ & $81.4 \pm 4.2^{\mathrm{b}}$ & $92.6 \pm 7.5^{\mathrm{c}}$ & $<0.001$ \\
\hline Ambulatory BP measurements & & & \\
\hline 24-h SBP, mmHg & $120.3 \pm 5.6^{\mathrm{a}}$ & $127.6 \pm 7.0^{\mathrm{b}}$ & $139.9 \pm 10.8^{\mathrm{c}}$ & $<0.001$ \\
24-h DBP, mmHg & $74.4 \pm 5.8^{\mathrm{a}}$ & $83.4 \pm 5.6^{\mathrm{b}}$ & $93.9 \pm 8.6^{\mathrm{c}}$ & $<0.001$ \\
Daytime SBP, mmHg & $123.5 \pm 6.6^{\mathrm{a}}$ & $132.8 \pm 7.7^{\mathrm{b}}$ & $144.9 \pm 11.6^{\mathrm{c}}$ & $<0.001$ \\
Daytime DBP, mmHg & $76.8 \pm 5.7^{\mathrm{a}}$ & $87.5 \pm 6.0^{\mathrm{b}}$ & $98.0 \pm 9.2^{\mathrm{c}}$ & $<0.001$ \\
Nighttime SBP, mmHg & $113.3 \pm 8.3^{\mathrm{a}}$ & $118.6 \pm 10.5^{\mathrm{b}}$ & $130.4 \pm 13.5^{\mathrm{c}}$ & $<0.001$ \\
Nighttime DBP, mmHg & $69.6 \pm 6.6^{\mathrm{a}}$ & $76.0 \pm 7.7^{\mathrm{b}}$ & $86.1 \pm 10.5^{\mathrm{c}}$ & $<0.001$ \\
\hline Aorta BP measurements & & & \\
\hline Aorta SBP, mmHg & $124.1 \pm 8.1^{\mathrm{a}}$ & $127.7 \pm 8.3^{\mathrm{b}}$ & $136.3 \pm 10.1^{\mathrm{c}}$ & $<0.001$ \\
\hline
\end{tabular}

Data are presented as mean \pm standard deviation or number (percentage). ${ }^{*} p$-value given by the analysis of variance, where the different superscript alphabets $(a, b$, and c) represent significant differences at an alpha level of 0.05 , as given by the post hoc Tukey's HSD analysis. Abbreviations: BP, blood pressure; SBP, systolic blood pressure; DBP, diastolic blood pressure. 


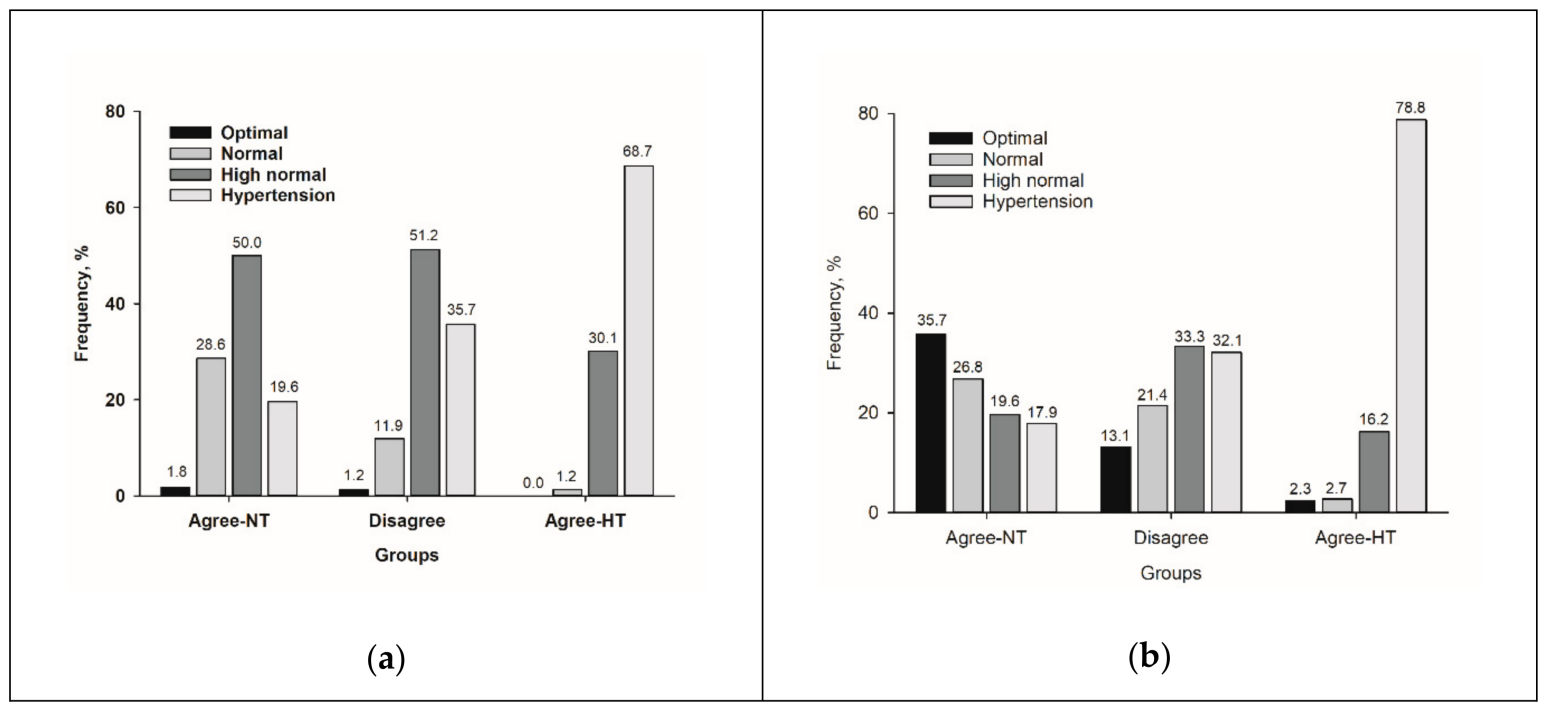

Figure 2. Distributions of office (a) systolic and (b) diastolic BP classification. Abbreviations: BP, blood pressure; Agree-NT, home and daytime ambulatory normotension; Disagree, home normotension and daytime ambulatory hypertension, or home hypertension and daytime ambulatory normotension; Agree-HT, home and daytime ambulatory hypertension.

\subsection{Determinants of the Difference between the Home and Ambulatory BP}

In the linear regression analysis, alcohol drinking was significantly associated with an SBP difference between the home and ambulatory BP, and the office BP with a DBP difference, respectively (Table 3). In the generalized multinomial logistic regression analysis for the three diagnostic categories, the variables—except for home and ambulatory BP—showed no significant odds ratio for the Disagree group compared to the Agree-NT or the Agree-HT group (Table 4).

Table 3. Determinants of the differences between the home and ambulatory blood pressure, as determined by the linear regression analysis.

\begin{tabular}{ccc}
\hline \multirow{2}{*}{ Variable } & \multicolumn{2}{c}{ Standardized Beta Coefficient } \\
\cline { 2 - 3 } & Systolic BP Difference & Diastolic BP Difference \\
\hline Age & 0.06 & -0.15 \\
Sex & 0.07 & 0.13 \\
BMI & -0.03 & -0.07 \\
Smoking & -0.06 & -0.07 \\
Alcohol drinking & $0.14^{*}$ & 0.06 \\
Diabetes & -0.07 & 0.00 \\
eGFR & -0.10 & -0.11 \\
Office BP & 0.08 & $-0.14 *$ \\
ECG voltage & -0.10 & -0.03 \\
\hline
\end{tabular}

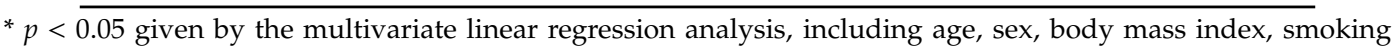
status, alcohol drinking, diabetes mellitus, the estimated glomerular filtration rate (eGFR) as given by the CKD-EPI creatinine equation, office blood pressure, and electrocardiographic Sokolow-Lyon voltage. The office systolic blood pressure for the systolic blood pressure difference and the office diastolic blood pressure for the diastolic blood pressure difference were included as covariates. The electrocardiogram (ECG) voltages were calculated using the Sokolow-Lyon voltage (defined as the voltage of the $\mathrm{S}$ wave in V1 + the voltage of the R wave in V5 or V6). Abbreviations: BP, blood pressure; BMI, body mass index; eGFR, estimated glomerular filtration rate; ECG, electrocardiogram. 
Table 4. Determinants of the diagnostic disagreement between home and ambulatory measurements, as determined by the logistic regression analysis.

\begin{tabular}{|c|c|c|c|c|}
\hline \multirow[t]{2}{*}{ Variable } & \multicolumn{2}{|c|}{$\begin{array}{c}\text { Odd Ratio of the Disagree Group versus } \\
\text { the Agree-NT Group }\end{array}$} & \multicolumn{2}{|c|}{$\begin{array}{c}\text { Odd Ratio of the Disagree Group versus } \\
\text { the Agree-HT Group }\end{array}$} \\
\hline & Model1 & Model2 & Model1 & Model2 \\
\hline Age & $0.98(0.93-1.03)$ & $0.92(0.84-1.01)$ & $0.98(0.94-1.02)$ & $0.99(0.93-1.06)$ \\
\hline Sex & $0.62(0.27-1.45)$ & $0.93(0.24-3.68)$ & $1.10(0.57-2.14)$ & $0.88(0.29-2.67)$ \\
\hline BMI & $0.95(0.85-1.07)$ & $1.06(0.89-1.27)$ & $0.96(0.88-1.05)$ & $1.11(0.94-1.30)$ \\
\hline Smoking & $0.71(0.13-4.02)$ & $0.48(0.01-35.52)$ & $2.26(0.85-6.01)$ & $1.04(0.27-4.06)$ \\
\hline Alcohol drinking & $1.05(0.47-2.33)$ & $0.60(0.16-2.25)$ & $0.81(0.43-1.54)$ & $0.83(0.30-2.27)$ \\
\hline eGFR & $1.01(0.98-1.05)$ & $0.99(0.93-1.06)$ & $1.00(0.97-1.02)$ & $1.00(0.97-1.04)$ \\
\hline Office SBP & $0.99(0.93-1.04)$ & $1.00(0.89-1.13)$ & $1.07(1.02-1.11)$ & $1.06(0.96-1.16)$ \\
\hline Office DBP & $0.90(0.83-0.97)$ & $1.01(0.85-1.20)$ & $1.16(1.09-1.24)$ & $1.05(0.91-1.21)$ \\
\hline Diabetes & $0.36(0.07-1.86)$ & $0.31(0.03-3.45)$ & $0.98(0.37-2.58)$ & $0.77(0.16-3.65)$ \\
\hline Home SBP & & $0.90(0.78-1.04)$ & & $1.27(1.13-1.43)^{*}$ \\
\hline Home DBP & & $0.84(0.67-1.05)$ & & $1.46(1.23-1.73)$ * \\
\hline Daytime SBP & & $0.85(0.75-0.95)$ * & & $1.06(0.98-1.15)$ \\
\hline Daytime DBP & & $0.70(0.59-0.83)$ * & & $1.16(1.02-1.31)$ * \\
\hline
\end{tabular}

\subsection{Comparisons of the BP variability among the Groups}

The BP variabilities of each group are summarized in Table 6. There were no differences in the intra-visit and inter-visit office BP variabilities among the groups. For the home BP variabilities, the standard deviations of SBP and DBP in the Disagree group were significantly lower than those in the Agree-HT group for the morning and evening measurements, but were not significantly different from those in the Agree-NT group. The standard deviations for 24-h, daytime, and nighttime, and the weighted standard deviation of the 24-h ambulatory BP in the Disagree group were intermediate between those in the Agree-NT and the Agree-HT groups.

Table 5. Comparisons of the blood pressure variability.

\begin{tabular}{|c|c|c|c|c|}
\hline BP Variability & $\begin{array}{c}\text { Agree-NT } \\
(N=56)\end{array}$ & $\begin{array}{l}\text { Disagree } \\
(N=84)\end{array}$ & $\begin{array}{c}\text { Agree-HT } \\
(N=259)\end{array}$ & $p$-Value * \\
\hline \multicolumn{5}{|l|}{ Office BP variability } \\
\hline Standard deviation of SBP, intra-visit, $\mathrm{mmHg}$ & $4.86 \pm 1.80$ & $4.73 \pm 1.80$ & $4.63 \pm 1.77$ & 0.665 \\
\hline Standard deviation of DBP, intra-visit, $\mathrm{mmHg}$ & $2.73 \pm 1.26$ & $2.62 \pm 1.12$ & $2.86 \pm 1.22$ & 0.259 \\
\hline Standard deviation of SBP, inter-visit, $\mathrm{mmHg}$ & $7.57 \pm 3.82$ & $7.67 \pm 4.28$ & $7.18 \pm 4.53$ & 0.611 \\
\hline Standard deviation of DBP, inter-visit, $\mathrm{mmHg}$ & $4.65 \pm 2.65$ & $4.25 \pm 2.53$ & $4.54 \pm 2.45$ & 0.565 \\
\hline \multicolumn{5}{|l|}{ Home BP variability } \\
\hline Standard deviation of SBP, $\mathrm{mmHg}$ & $8.57 \pm 2.30^{a}$ & $8.43 \pm 2.00^{\mathrm{a}}$ & $9.74 \pm 2.82^{b}$ & $<0.001$ \\
\hline Standard deviation of $\mathrm{DBP}, \mathrm{mmHg}$ & $5.23 \pm 1.38^{a}$ & $5.41 \pm 1.53^{\mathrm{a}}$ & $6.19 \pm 2.46^{b}$ & 0.001 \\
\hline Standard deviation of SBP, morning, $\mathrm{mmHg}$ & $7.20 \pm 2.58^{a}$ & $7.13 \pm 2.02^{a}$ & $8.14 \pm 2.60^{b}$ & 0.001 \\
\hline Standard deviation of DBP, morning, $\mathrm{mmHg}$ & $4.39 \pm 1.66$ & $4.69 \pm 1.82$ & $5.07 \pm 2.12$ & 0.043 \\
\hline Standard deviation of SBP, evening, $\mathrm{mmHg}$ & $8.28 \pm 2.60^{a}$ & $8.49 \pm 2.52^{a}$ & $9.77 \pm 3.51^{b}$ & $<0.001$ \\
\hline Standard deviation of DBP, evening, $\mathrm{mmHg}$ & $5.16 \pm 1.71^{\mathrm{a}}$ & $5.38 \pm 1.53^{\mathrm{a}}$ & $6.40 \pm 3.26^{b}$ & 0.001 \\
\hline
\end{tabular}


Table 6. Comparisons of the blood pressure variability.

\begin{tabular}{|c|c|c|c|c|}
\hline BP Variability & $\begin{array}{c}\text { Agree-NT } \\
(N=56)\end{array}$ & $\begin{array}{l}\text { Disagree } \\
(N=84)\end{array}$ & $\begin{array}{c}\text { Agree-HT } \\
(N=259)\end{array}$ & $p$-Value * \\
\hline \multicolumn{5}{|l|}{ Ambulatory BP variability } \\
\hline Standard deviation of 24-h SBP, mmHg & $13.4 \pm 3.7^{\mathrm{a}}$ & $14.3 \pm 3.7^{\mathrm{a}, \mathrm{b}}$ & $15.6 \pm 4.6^{\mathrm{b}}$ & 0.001 \\
\hline Standard deviation of $24-\mathrm{h} \mathrm{DBP}, \mathrm{mmHg}$ & $9.5 \pm 2.4^{\mathrm{a}}$ & $11.1 \pm 2.5^{b}$ & $12.0 \pm 3.0^{\mathrm{c}}$ & $<0.001$ \\
\hline Standard deviation of daytime SBP, $\mathrm{mmHg}$ & $12.6 \pm 4.0$ & $12.5 \pm 4.4$ & $13.7 \pm 4.9$ & 0.043 \\
\hline Standard deviation of daytime $\mathrm{DBP}, \mathrm{mmHg}$ & $8.9 \pm 2.7^{a}$ & $9.4 \pm 3.1^{\mathrm{a}, \mathrm{b}}$ & $10.1 \pm 3.2^{b}$ & 0.017 \\
\hline Standard deviation of nighttime SBP, $\mathrm{mmHg}$ & $9.9 \pm 4.3^{\mathrm{a}}$ & $10.4 \pm 3.9^{\mathrm{a}, \mathrm{b}}$ & $11.5 \pm 4.4^{\mathrm{b}}$ & 0.012 \\
\hline Standard deviation of nighttime $\mathrm{DBP}, \mathrm{mmHg}$ & $7.7 \pm 2.7^{\mathrm{a}}$ & $8.4 \pm 2.9^{\mathrm{a}}$ & $9.6 \pm 3.3^{b}$ & $<0.001$ \\
\hline Weighted standard deviation of 24-h SBP, mmHg & $11.7 \pm 3.5^{\mathrm{a}}$ & $11.8 \pm 3.3^{\mathrm{a}, \mathrm{b}}$ & $13.0 \pm 3.8^{b}$ & 0.005 \\
\hline Weighted standard deviation of 24-h DBP, $\mathrm{mmHg}$ & $8.5 \pm 2.3^{\mathrm{a}}$ & $9.1 \pm 2.4^{\mathrm{a}, \mathrm{b}}$ & $9.9 \pm 2.6^{b}$ & $<0.001$ \\
\hline
\end{tabular}

Data are presented as means \pm standard deviation or numbers (percentages). * $p$-value given by the analysis of variance, where the different superscript alphabets $(a, b$, and $c)$ represent significant differences at an alpha level of 0.05 , as given by the post hoc Tukey's HSD analysis. Abbreviations: BP, blood pressure; SBP, systolic blood pressure; DBP, diastolic blood pressure.

\subsection{Subgroup Analysis of the Disagree Group}

In the Disagree group, 17 individuals $(20.2 \%)$ had home BP hypertension and 67 individuals $(79.8 \%)$ had ambulatory BP hypertension. The clinical characteristics and laboratory findings were not significantly different between these two groups (Table 7). The office BP was also not different between the groups. However, the home BP values were higher in the home BP hypertension group, and the 24-h, daytime and nighttime ambulatory BP values were higher in the ambulatory BP hypertension group. On the other hand, the nighttime ambulatory BP values were not different between these two groups.

Table 7. Demographic and clinical characteristics of the individuals in the Disagree group.

\begin{tabular}{|c|c|c|c|}
\hline & $\begin{array}{l}\text { HBP Hypertension } \\
(N=17)\end{array}$ & $\begin{array}{l}\text { ABP Hypertension } \\
(N=67)\end{array}$ & $p$-Value \\
\hline \multicolumn{4}{|l|}{ Clinical characteristics } \\
\hline Age, years & $58.8 \pm 10.4$ & $54.5 \pm 8.2$ & 0.073 \\
\hline Male & $8(47.1 \%)$ & $28(41.8 \%)$ & 0.695 \\
\hline Body mass index, $\mathrm{kg} / \mathrm{m}^{2}$ & $25.0 \pm 3.9$ & $25.1 \pm 3.5$ & 0.916 \\
\hline Diabetes mellitus & $2(11.8 \%)$ & $7(10.6 \%)$ & 0.891 \\
\hline \multicolumn{4}{|l|}{ Laboratory findings } \\
\hline Creatinine, $\mathrm{mg} / \mathrm{dL}$ & $0.81 \pm 0.24$ & $0.76 \pm 0.19$ & 0.351 \\
\hline Glucose, $\mathrm{mg} / \mathrm{dL}$ & $103.2 \pm 11.0$ & $103.0 \pm 17.9$ & 0.967 \\
\hline Hemoglobin A1c, \% & $5.66 \pm 0.40$ & $5.70 \pm 0.81$ & 0.853 \\
\hline Total cholesterol, mg/dL & $194.1 \pm 33.6$ & $194.3 \pm 33.2$ & 0.983 \\
\hline Triglycerides, mg/dL & $124.7 \pm 69.5$ & $134.8 \pm 62.1$ & 0.558 \\
\hline HDL-cholesterol, mg/dL & $50.8 \pm 15.9$ & $55.9 \pm 12.9$ & 0.176 \\
\hline LDL-cholesterol, mg/dL & $134.5 \pm 33.3$ & $130.6 \pm 30.5$ & 0.647 \\
\hline Urine albumin-to-creatinine ratio & $22.8 \pm 55.1$ & $26.5 \pm 112.4$ & 0.896 \\
\hline ECG voltage, $\mathrm{mm}$ & $24.2 \pm 10.5$ & $22.8 \pm 6.5$ & 0.504 \\
\hline \multicolumn{4}{|l|}{ BP measurements } \\
\hline Office SBP, mmHg & $139.0 \pm 7.3$ & $137.0 \pm 7.9$ & 0.356 \\
\hline Office DBP, $\mathrm{mmHg}$ & $86.6 \pm 5.8$ & $87.1 \pm 5.6$ & 0.747 \\
\hline Home SBP, mmHg & $134.7 \pm 4.8$ & $126.1 \pm 5.7$ & $<0.001$ \\
\hline Home DBP, mmHg & $85.2 \pm 5.6$ & $80.5 \pm 3.1$ & 0.004 \\
\hline 24-h SBP, mmHg & $123.6 \pm 5.8$ & $128.6 \pm 6.9$ & 0.007 \\
\hline 24-h DBP, mmHg & $77.8 \pm 4.9$ & $84.9 \pm 4.8$ & $<0.001$ \\
\hline
\end{tabular}


Table 7. Cont.

\begin{tabular}{cccc}
\hline & $\begin{array}{c}\text { HBP Hypertension } \\
(\boldsymbol{N}=\mathbf{1 7})\end{array}$ & $\begin{array}{c}\text { ABP Hypertension } \\
(\boldsymbol{N}=\mathbf{6 7})\end{array}$ & $\boldsymbol{p}$-Value \\
\hline BP measurements & & & \\
\hline Daytime SBP, mmHg & $125.7 \pm 4.7$ & $134.6 \pm 7.3$ & $<0.001$ \\
Daytime DBP, $\mathrm{mmHg}$ & $77.8 \pm 4.9$ & $84.9 \pm 4.8$ & $<0.001$ \\
Nighttime SBP, mmHg & $118.2 \pm 9.1$ & $118.7 \pm 10.8$ & 0.868 \\
Nighttime DBP, mmHg & $73.1 \pm 8.5$ & $76.8 \pm 7.3$ & 0.080 \\
Aorta SBP, mmHg & $129.2 \pm 7.2$ & $127.4 \pm 8.5$ & 0.431 \\
\hline
\end{tabular}

Data are presented as means \pm standard deviation, or numbers (percentages). The ECG voltages were calculated using the Sokolow-Lyon voltage (defined as the voltage of the $\mathrm{S}$ wave in V1 + the voltage of the $\mathrm{R}$ wave in V5 or V6). Abbreviations: BP, blood pressure; HDL-cholesterol, high-density lipoprotein cholesterol; LDL-cholesterol, low-density lipoprotein cholesterol; ECG, electrocardiogram; SBP, systolic blood pressure; DBP, diastolic blood pressure.

The analysis of the diagnosis based on the 24-h ambulatory BP showed similar results to the analysis of the diagnosis based on the daytime ambulatory BP (data not shown).

\section{Discussion}

The major findings of our study are as follows: (1) the mean office and home DBP in the Disagree group were higher than those in the Agree-NT group; (2) the mean ambulatory SBP and DBP, and the aortic SBP in the Disagree group differed significantly, and were intermediate between those in the Agree-NT and the Agree-HT groups; (3) no consistent clinical or demographic characteristics were identified to be determinants of the BP differences and the diagnostic disagreement between the home and ambulatory BP measurements; and (4) the ambulatory BP variabilities and the ECG voltage of the Disagree group were intermediate between those of the Agree-NT and the Agree-HT groups.

The guidelines recommend out-of-office BP measurements for the optimal diagnosis and treatment of hypertension, because they are more closely associated with cardiovascular outcomes than office BP measurements, and enable white-coat and masked hypertension to be identified [1,3]. Home and ambulatory BP measurements are the representative out-of-office BP measurement methods. Although ambulatory BP measurements are better for cardiovascular risk prediction than home BP measurements [9], the inconvenience and cost are major limitations of using ambulatory BP measurements in clinical practice. Hence, home BP measurements may be used in the diagnosis of hypertension phenotypes. However, the interchangeability of the home and ambulatory BP measurements in the diagnosis of hypertension is controversial because of the diagnostic disagreement between both methods $[10,11]$. The diagnostic disagreement between the two methods may be problematic in clinical practice because doctors and patients may require treatment decisions based on a clear diagnosis. In addition, the diagnostic disagreement between the home and ambulatory daytime BP measurements is not uncommon, and may lead to misdiagnoses and mistreatments. Therefore, the prediction of patients with diagnostic disagreement, and their risk of cardiovascular disease, would be of great importance in clinical practice.

Few studies have sought to identify the determinants of the diagnostic disagreement. Ntineri et al. found that age, sex, antihypertensive drug treatment, centers, body mass index and office hypertension were associated with the difference between home and daytime ambulatory BP, and antihypertensive drug treatment, alcohol consumption, and office normotension were major determinants of the diagnostic disagreement between home and daytime ambulatory BP measurements [12]. However, we failed to identify any demographic or clinical feature that was capable of distinguishing individuals with diagnostic disagreement between their home and ambulatory BP measurements. A linear regression analysis also failed to identify any factor consistently associated with differences between home and daytime ambulatory BP. Furthermore, the logistic regression analysis showed that home and ambulatory BP were the only significant determinants of diagnostic disagreement between home 
and ambulatory BP measurements, which suggests that it may be difficult to predict diagnostic disagreement without home and ambulatory BP results. Although ambulatory BP, office and home DBP showed statistical differences in their values according to the groups, there was considerable overlap. The different results between Ntineri's and our study may be explained by the difference of the study populations. Ntineri's study included patients on antihypertensive drug treatment (32\% of the study population) [12], whereas we excluded patients on antihypertensive drug treatments. Our study results indicate that it is difficult to distinguish patients with a diagnostic disagreement between their home and ambulatory BP measurements using clinical and demographic characteristics.

A diagnostic disagreement based on home and ambulatory BP measurements may partly be explained by a lack of measurement reproducibility and methodological differences. Previous studies have reported standard deviations for test-retest daytime ambulatory BP of 10 to $12 \mathrm{mmHg}$ for SBP and $7 \mathrm{mmHg}$ for DBP [13-15], and standard deviations for test-retest home SBP and DBP of 6.9 and $4.7 \mathrm{mmHg}$, respectively [15]. In another study, the diagnosis of masked hypertension using repeated office, home, and ambulatory BP measurements showed fair-to-moderate reproducibility [16]. In the present study, the home BP was measured between 7 and $9 \mathrm{am}$, or within $2 \mathrm{~h}$ of waking up, and between 9 and $11 \mathrm{pm}$, or before bedtime, while the daytime ambulatory BP was the averaged BP obtained between 9 am and $9 \mathrm{pm}$. The BP being measured at different times may also be a cause of the diagnostic disagreement between home and ambulatory BP measurements.

Although we were unable to identify the differentiating features, the intermediate level of the ambulatory BP parameters, the central aortic SBP, and the ambulatory BP variability in the Disagree group being situated between the Agree-NT and the Agree-HT groups suggest that individuals with a diagnostic disagreement between their home and ambulatory BP measurements may also be at an intermediate cardiovascular risk between sustained home and ambulatory normotension and hypertension. Therefore, a diagnostic disagreement between home BP and ambulatory BP measurements may not absolve individuals of cardiovascular risk, and these individuals should not be classified as 'normotensives'.

We averaged all three readings of the home BP measurements instead of discarding the first reading and averaging the next two readings, because there was no difference in the diagnostic accuracy and reliability between the two methods in our previous study [7].

The present study has a number of limitations that deserve consideration. First, we conducted the analysis using the daytime ambulatory $\mathrm{BP}$, because both the home and daytime ambulatory BP reflect $\mathrm{BP}$ during waking hours, and the same BP threshold is used to diagnose hypertension. All or each of the 24-h, daytime, and/or nighttime ambulatory BP can be used in the diagnosis of hypertension. Previous studies have shown that 24-h and nighttime ambulatory BP are more associated with the prognosis than daytime ambulatory BP $[4,9,17]$. However, the results of the secondary analysis using diagnosis by $24-\mathrm{h}$ ambulatory BP in our study were not different to the primary analysis. Isolated nocturnal hypertension has also been shown to be associated with the risk of cardiovascular events [18], and the inclusion of nighttime BP or isolated nocturnal hypertension in the diagnosis of hypertension may be better than diagnosis based only on the daytime ambulatory BP. The inclusion of isolated nocturnal hypertension in the diagnosis of hypertension would probably increase the diagnostic disagreement rate, because individuals with isolated nocturnal hypertension in our study $(n=39)$ had a higher frequency of normotension diagnosis based on home BP in our study population (76.9\%). Additional studies are needed in order to determine the ways in which to interpret a diagnostic disagreement between BP measurements made at different times. Second, the daytime was determined by a fixed time period, not by the individuals' diaries. Therefore, the home and daytime ambulatory BP measured at different times were used in the diagnosis of hypertension, although both BP were measured during waking hours. Unlike people living in the West, many Koreans eat dinner out, and therefore the measurements of the home BP before dinner that are recommended by European hypertension guidelines [19] are difficult. Third, this cross-sectional study was conducted on individuals suspected to have hypertension. Although the individuals with diagnostic disagreement seemed to have intermediate cardiovascular 
risk between sustained home and ambulatory normotension and hypertension, their long-term risk should be determined. Fourth, the small sample size of this study may not be enough to evaluate the difference between individuals with home BP hypertension and ambulatory BP hypertension in the Disagree group.

\section{Conclusions}

Individuals showing diagnostic disagreement between home and ambulatory BP measurements may be at an intermediate cardiovascular risk compared with those with sustained home and daytime ambulatory normotension and hypertension. However, the differentiation of the clinical and demographic features of the disagreement between the home and ambulatory BP measurements could not be accomplished. Further research is needed to reduce the diagnostic disagreement between home and ambulatory BP measurements, and to develop methods that can distinguish individuals with diagnostic disagreement.

Author Contributions: M.-Y.R.: conceptualization, methodology, investigation, formal analysis, writing-review and editing; C.H.K.: formal analysis, writing—original draft preparation; J.S.K.: formal analysis, writing—review and editing. All authors have read and agreed to the published version of the manuscript.

Funding: This research received no external funding.

Conflicts of Interest: The authors declare no conflict of interest.

\section{References}

1. Whelton, P.K.; Carey, R.M.; Aronow, W.S.; Casey, D.E.; Collins, K.J.; Himmelfarb, C.D.; DePalma, S.M.; Gidding, S.; Jamerson, K.A.; Jones, D.W. 2017 ACC/AHA/AAPA/ABC/ACPM/AGS /APhA/ASH/ASPC/NMA/PCNA guideline for the prevention, detection, evaluation, and management of high blood pressure in adults: A report of the American College of Cardiology/American Heart Association Task Force on Clinical Practice Guidelines. J. Am. Coll. Cardiol. 2018, 71, e127-e248.

2. Muntner, P.; Shimbo, D.; Carey, R.M.; Charleston, J.B.; Gaillard, T.; Misra, S.; Myers, M.G.; Ogedegbe, G.; Schwartz, J.E.; Townsend, R.R. Measurement of blood pressure in humans: A scientific statement from the American Heart Association. Hypertension 2019, 73, e35-e66. [CrossRef]

3. Williams, B.; Mancia, G.; Spiering, W.; Agabiti Rosei, E.; Azizi, M.; Burnier, M.; Clement, D.L.; Coca, A.; De Simone, G.; Dominiczak, A. 2018 ESC/ESH Guidelines for the management of arterial hypertension: The Task Force for the management of arterial hypertension of the European Society of Cardiology (ESC) and the European Society of Hypertension (ESH). Euro. Heart. J. 2018, 39, 3021-3104. [CrossRef] [PubMed]

4. Banegas, J.R.; Ruilope, L.M.; de la Sierra, A.; Vinyoles, E.; Gorostidi, M.; de la Cruz, J.J.; Ruiz-Hurtado, G.; Segura, J.; Rodríguez-Artalejo, F.; Williams, B. Relationship between clinic and ambulatory blood-pressure measurements and mortality. N. Engl. J. Med. 2018, 378, 1509-1520. [CrossRef] [PubMed]

5. Niiranen, T.J.; Hänninen, M.-R.; Johansson, J.; Reunanen, A.; Jula, A.M. Home-measured blood pressure is a stronger predictor of cardiovascular risk than office blood pressure: The Finn-Home study. Hypertension 2010, 55, 1346-1351. [CrossRef] [PubMed]

6. Mortensen, R.N.; Gerds, T.A.; Jeppesen, J.L.; Torp-Pedersen, C. Office blood pressure or ambulatory blood pressure for the prediction of cardiovascular events. Euro. Heart. J. 2017, 38, 3296-3304. [CrossRef] [PubMed]

7. Rhee, M.Y.; Kim, J.Y.; Kim, J.H.; Namgung, J.; Lee, S.Y.; Cho, D.K.; Choi, T.Y.; Kim, S.Y. Optimal schedule of home blood-pressure measurements for the diagnosis of hypertension. Hypertens. Res. 2018, 41, 738-747. [CrossRef]

8. $\quad$ Park, J.S.; Rhee, M.Y.; Namgung, J.; Lee, S.Y.; Cho, D.K.; Choi, T.Y.; Kim, S.Y.; Kim, J.Y.; Park, S.M.; Choi, J.H.; et al. Comparison of Optimal Diagnostic Thresholds of Hypertension With Home Blood Pressure Monitoring and 24-Hour Ambulatory Blood Pressure Monitoring. Am. J. Hypertens. 2017, 30, 1170-1176. [CrossRef] [PubMed] 
9. Sega, R.; Facchetti, R.; Bombelli, M.; Cesana, G.; Corrao, G.; Grassi, G.; Mancia, G. Prognostic value of ambulatory and home blood pressures compared with office blood pressure in the general population: Follow-up results from the Pressioni Arteriose Monitorate e Loro Associazioni (PAMELA) study. Circulation 2005, 111, 1777-1783. [CrossRef] [PubMed]

10. Hodgkinson, J.; Mant, J.; Martin, U.; Guo, B.; Hobbs, F.D.; Deeks, J.J.; Heneghan, C.; Roberts, N.; McManus, R.J. Relative effectiveness of clinic and home blood pressure monitoring compared with ambulatory blood pressure monitoring in diagnosis of hypertension: Systematic review. BMJ 2011, 342, d3621. [CrossRef] [PubMed]

11. Kang, Y.Y.; Li, Y.; Huang, Q.F.; Song, J.; Shan, X.L.; Dou, Y.; Xu, X.J.; Chen, S.H.; Wang, J.G. Accuracy of home versus ambulatory blood pressure monitoring in the diagnosis of white-coat and masked hypertension. J. Hypertens. 2015, 33, 1580-1587. [CrossRef] [PubMed]

12. Ntineri, A.; Niiranen, T.J.; McManus, R.J.; Lindroos, A.; Jula, A.; Schwartz, C.; Kollias, A.; Andreadis, E.A.; Stergiou, G.S. Ambulatory versus home blood pressure monitoring: Frequency and determinants of blood pressure difference and diagnostic disagreement. J. Hypertens. 2019, 37, 1974-1981. [CrossRef] [PubMed]

13. Eguchi, K.; Hoshide, S.; Hoshide, Y.; Ishikawa, S.; Shimada, K.; Kario, K. Reproducibility of ambulatory blood pressure in treated and untreated hypertensive patients. J. Hypertens. 2010, 28, 918-924. [CrossRef] [PubMed]

14. Van der Steen, M.S.; Lenders, J.W.; Graafsma, S.J.; den Arend, J.; Thien, T. Reproducibility of ambulatory blood pressure monitoring in daily practice. J. Hum. Hypertens. 1999, 13, 303-308. [CrossRef] [PubMed]

15. Stergiou, G.S.; Baibas, N.M.; Gantzarou, A.P.; Skeva, I.I.; Kalkana, C.B.; Roussias, L.G.; Mountokalakis, T.D. Reproducibility of home, ambulatory, and clinic blood pressure: Implications for the design of trials for the assessment of antihypertensive drug efficacy. Am. J. Hypertens. 2002, 15, 101-104. [CrossRef]

16. Viera, A.J.; Hinderliter, A.L.; Kshirsagar, A.V.; Fine, J.; Dominik, R. Reproducibility of masked hypertension in adults with untreated borderline office blood pressure: Comparison of ambulatory and home monitoring. Am. J. Hypertens. 2010, 23, 1190-1197. [CrossRef] [PubMed]

17. Fagard, R.H.; Celis, H.; Thijs, L.; Staessen, J.A.; Clement, D.L.; De Buyzere, M.L.; De Bacquer, D.A. Daytime and nighttime blood pressure as predictors of death and cause-specific cardiovascular events in hypertension. Hypertension 2008, 51, 55-61. [CrossRef] [PubMed]

18. Li, Y.; Staessen, J.A.; Lu, L.; Li, L.H.; Wang, G.L.; Wang, J.G. Is isolated nocturnal hypertension a novel clinical entity? Findings from a Chinese population study. Hypertension 2007, 50, 333-339. [CrossRef] [PubMed]

19. Parati, G.; Stergiou, G.S.; Asmar, R.; Bilo, G.; de Leeuw, P.; Imai, Y.; Kario, K.; Lurbe, E.; Manolis, A.; Mengden, T.; et al. European Society of Hypertension practice guidelines for home blood pressure monitoring. J. Hum. Hypertens. 2010, 24, 779-785. [CrossRef]

Publisher's Note: MDPI stays neutral with regard to jurisdictional claims in published maps and institutional affiliations.

(C) 2020 by the authors. Licensee MDPI, Basel, Switzerland. This article is an open access article distributed under the terms and conditions of the Creative Commons Attribution (CC BY) license (http://creativecommons.org/licenses/by/4.0/). 